\title{
BMJ Open Quality AMS in the ICU: empiric therapy and adherence to guidelines for pneumonia
}

\author{
Shelby Pflanzner, ${ }^{1}$ Casey Phillips, ${ }^{2}$ Jonathan Mailman, ${ }^{1,3}$ Jason Robert Vanstone ${ }^{\odot}$
}

To cite: Pflanzner S, Phillips C, Mailman J, et al. AMS in the ICU: empiric therapy and adherence to guidelines for pneumonia. BMJ Open Quality 2019;8:e000554. doi:10.1136/ bmjoq-2018-000554

Received 16 October 2018 Revised 21 March 2019 Accepted 10 April 2019

\section{INTRODUCTION}

Antimicrobial stewardship (AMS) aims to preserve the efficacy of antimicrobials by selecting the right drug, dose and duration for the appropriate indication, resulting in maximum benefit and minimising adverse events and development of antimicrobial resistance. ${ }^{12}$ While AMS interventions may appear to be at odds with practice in the intensive care unit (ICU), they can improve quality of care without compromising patient outcomes. ${ }^{2}$ This study assessed if empiric antimicrobial therapy aligned with guideline recommendations for critically ill patients with community-acquired pneumonia (CAP), hospital-acquired pneumonia (HAP), ventilator-associated pneumonia (VAP) or aspiration pneumonia.

\section{METHODS}

This retrospective chart review included patients discharged or expired from three mixed medical/surgical ICUs in Regina, Saskatchewan, Canada between October 2016 and March 2017. Patients were included if they were $\geq 18$ years old and had ICD-10 codes corresponding to pneumonia and an indication for pneumonia recorded in their chart; they were excluded if they were not in the ICU while being treated for pneumonia or for any subsequent ICU re-admissions (ie, index admission only). Records were assessed for antimicrobial alignment with guideline recommendations for each type of pneumonia. $^{3-5}$ If the regimen was not guideline concordant, further assessment by two clinical experts was conducted to determine if it was still clinically appropriate by taking into consideration local antibiogram patterns and other available patient-specific factors, such as allergies, recent antimicrobial exposure, suspected co-infections and concomitant disease states. This study was approved by the local research ethics board.
(A) Check for updates

(c) Author(s) (or their employer(s)) 2019. Re-use permitted under CC BY-NC. No commercial re-use. See rights and permissions. Published by BMJ.

${ }^{1}$ Department of Pharmacy Services, Saskatchewan Health Authority, Saskatoon, Saskatchewan, Canada ${ }^{2}$ Antimicrobial Stewardship Program, Saskatchewan Health Authority, Regina, Saskatchewan, Canada ${ }^{3}$ College of Medicine, University of Saskatchewan, Saskatoon, Saskatchewan, Canada ${ }^{4}$ Stewardship and Clinical Appropriateness, Saskatchewan Health Authority, Regina, Saskatchewan, Canada

Correspondence to Dr Jason Robert Vanstone; jason.vanstone@ saskhealthauthority.ca

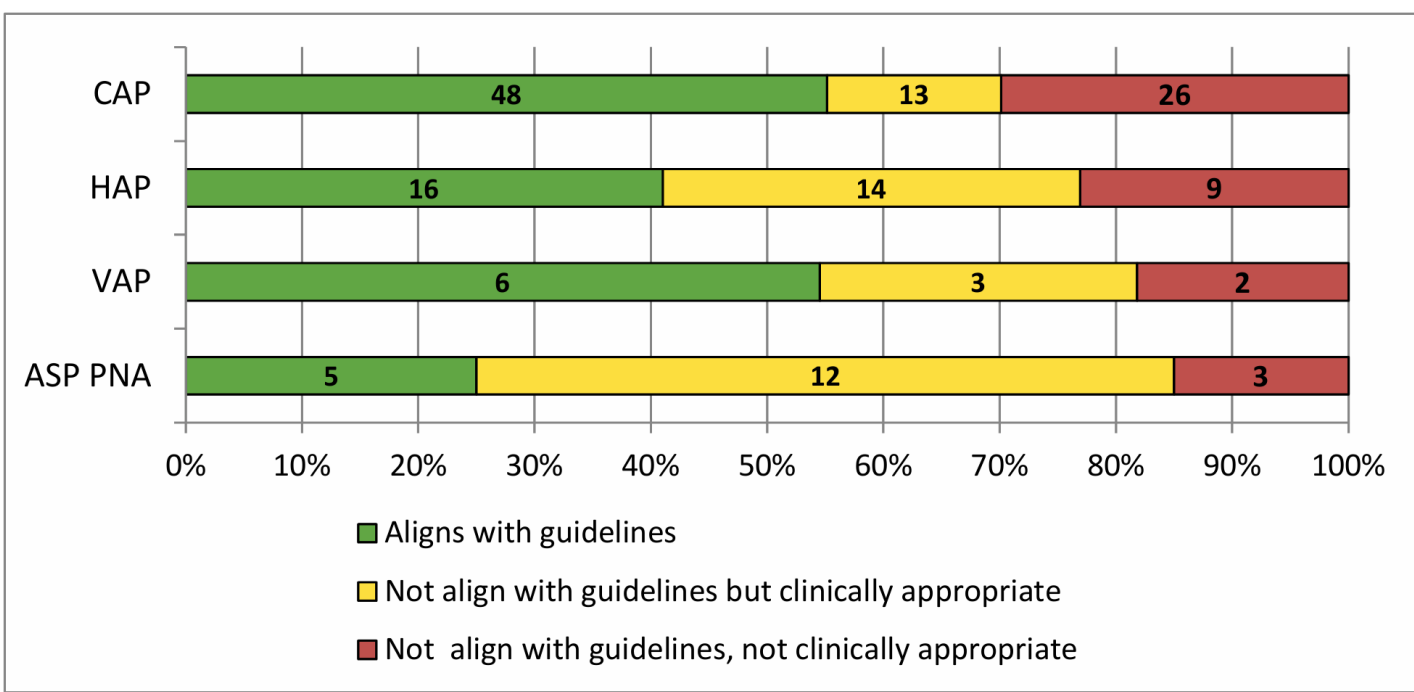

Figure 1 Compliance with empiric therapy guidelines for treatment of each type of pneumonia. Green bars indicate the proportion of patients where empiric therapy matched guideline recommendations. Yellow bars indicate the proportion of patients where empiric therapy did not match guideline recommendations, but therapy was deemed to be clinically appropriate based on other patient factors. Red bars indicate patients where empiric therapy did not match guidelines and was not otherwise considered clinically appropriate. The number in each bar indicates the number of patients for that category. ASP PNA, aspiration pneumonia; CAP, community-acquired pneumonia; HAP, hospital-acquired pneumonia; VAP, ventilator-associated pneumonia. 
Table 1 Reasons for guideline non-compliance for empiric therapy of pneumonia

\begin{tabular}{lllll}
\hline Total cases & CAP $(\mathbf{n = 8 7})$ & HAP (n=39) & VAP (n=11) & $\begin{array}{l}\text { ASP } \\
(\mathbf{n}=\mathbf{2 0})\end{array}$ \\
\hline Empiric regimen not aligning with guidelines & $39(45 \%)$ & $23(59 \%)$ & $5(45 \%)$ & $15(75 \%)$ \\
\hline Did not include atypical coverage & $18(46 \%)$ & - & - & - \\
\hline Not recommended by IDSA & $10(26 \%)$ & $13(57 \%)$ & - & - \\
Added vancomycin unnecessarily & $2(5 \%)$ & - & - & - \\
No beta-lactam included & $4(10 \%)$ & $2(9 \%)$ & - & - \\
Did not include MRSA ${ }^{*}$ coverage & - & $6(26 \%)$ & $2(40 \%)$ & - \\
Other & $5(13 \%)$ & $2(9 \%)$ & $3(60 \%)$ & - \\
\hline
\end{tabular}

*Local MRSA incidence: $27 \%$.

ASP, aspiration pneumonia; CAP, community-acquired pneumonia; HAP, hospital-acquired pneumonia; IDSA, Infectious Diseases Society of America; MRSA, methicillin-resistant Staphylococcus aureus ; VAP, ventilator-associated pneumonia.

\section{RESULTS}

There were 157 patients included in this study. The mean age was 62 years $( \pm 16.3)$ with $41 \%$ female patients. In total, $55 \%(87 / 157)$ of patients were treated for CAP, $25 \%(39 / 157)$ for HAP, $7 \%(11 / 157)$ for VAP and $13 \%$ (20/157) for aspiration pneumonia.

In patients treated for CAP, $55 \%$ of the empiric therapy regimens aligned with guidelines, $15 \%$ did not align with guidelines but were still considered clinically appropriate based on other patient factors and 30\% did not comply with guidelines and were not otherwise clinically appropriate (figure 1). Of the HAP cases, $41 \%$ aligned with guidelines, $36 \%$ did not align but were still clinically appropriate and 23\% were neither aligned nor clinically appropriate. In VAP cases, $55 \%$ aligned with guidelines, $27 \%$ were not aligned but still clinically appropriate and $18 \%$ did not align and were not clinically appropriate. For aspiration pneumonia, 25\% aligned with guidelines, $60 \%$ were not aligned but still clinically appropriate and $15 \%$ were neither aligned nor considered clinically appropriate. Overall, $25 \%$ of all pneumonia cases reviewed did not follow guidelines for empiric therapy and were not considered clinically appropriate (figure 1 , red bars).

\section{DISCUSSION}

Regarding the $25 \%$ of all pneumonia cases that did not follow guidelines for empiric therapy and were not considered otherwise clinically appropriate, the main reason for this was not including some recommended component of therapy (table 1). This information can help inform ICU clinicians about their current practice alignment with evidence-based standards of best practice.

While $52 \%$ of all pneumonia cases did not align with empiric therapy guideline recommendations (figure 1, red +yellow bars), $51 \%$ of those were still clinically appropriate (figure 1, yellow bars), indicating prescribers are individualising treatment for each patient to provide appropriate empiric antimicrobial therapy.

Our findings are similar to other observational studies for AMS in ICUs. A previous trial found empiric antimicrobials could be justified in $54 \%$ of cases, suggesting considerable potential overuse stemming from difficulties in diagnosing ICU-related infections and from the higher perceived risk of infection compared with the risks of potentially unnecessary antimicrobial therapy, representing a type of risk-aversive behaviour. ${ }^{6}$

Limitations of this study are worth noting. This small, retrospective, observational study lacks power to provide clear, generalisable conclusions. Data capture was also suboptimal to determine whether methicillin-resistant Staphylococcus aureus coverage in CAP was necessary. Additionally, charts reviewed were from October 2016 to March 2017, and the new Infectious Diseases Society of America guidelines were published in September 2016. Prescribers may not have adjusted their practice to reflect the new guidelines during the study period. Data collection was unable to capture a complete clinical status of each patient or account for the clinical judgement of clinicians and their rationale for prescribing. One strength was the review with clinical experts to further explore the appropriateness of therapy. This helped determine the relatively large proportion of cases which, while not strictly following guideline recommendations, were clinically appropriate.

This project was intended to be the initial step in an audit and feedback programme for our local prescribers, and due to staffing and programme changes, ongoing work on an automated, electronic audit and feedback system to provide timely information to physicians on a more frequent and real-time basis has not yet been undertaken. The data from this study were presented to the prescribers following the study's conclusion and used to initiate a discussion within the group about the variations in practice compared with guideline recommendations. A follow-up project was then conducted to review our time to antimicrobial administration, and quality improvement process mapping is underway to further optimise care.

This study provides evidence that ICU clinician behaviour does not always follow guideline recommendations; however, in many cases the chosen empiric therapy is clinically appropriate. With $25 \%$ of cases that 
were both guideline non-concordant and not otherwise clinically appropriate, there presents an opportunity for quality improvement initiatives to promote higher quality of care for patients. Finally, this study exemplifies one way in which AMS initiatives can be used in the ICU to promote optimal use of antimicrobials and better patient outcomes.

Contributors SP, CP, JM and JRV contributed to the conception and design of the study. SP performed chart audits and data analysis. CP and JM reviewed cases as clinical experts. SP, CP, JM and JRV contributed to the final manuscript.

Funding This work was supported by the Regina Qu'Appelle Health RegionRegina Summer Student Program.

Competing interests None declared.

Patient consent for publication Not required.

Provenance and peer review Not commissioned; externally peer reviewed.

Open access This is an open access article distributed in accordance with the Creative Commons Attribution Non Commercial (CC BY-NC 4.0) license, which permits others to distribute, remix, adapt, build upon this work non-commercially, and license their derivative works on different terms, provided the original work is properly cited, appropriate credit is given, any changes made indicated, and the use is non-commercial. See: http://creativecommons.org/licenses/by-nc/4.0/.

\section{REFERENCES}

1. Doernberg SB, Chambers HF. Antimicrobial stewardship approaches in the intensive care unit. infect dis clin North am. United States 2017;31:513-34.

2. Gerding DN. The search for good antimicrobial stewardship. Jt Comm J Qual Improv 2001;27:403-4.

3. Mandell LA, Wunderink RG, Anzueto A, et al. Infectious diseases Society of America/American Thoracic Society consensus Guidelines on the management of community-acquired pneumonia in adults. Clin Infect Dis 2007;44(Suppl 2):S27-S72.

4. Kalil AC, Metersky ML, Klompas M, et al. Management of adults with hospital-acquired and ventilator-associated pneumonia: 2016 clinical practice guidelines by the infectious diseases Society of America and the American Thoracic Society. Clin Infect Dis 2016;63:e61-111.

5. American Thoracic Society, Infectious Diseases Society of America. Guidelines for the management of adults with hospital-acquired, ventilator-associated, and healthcare-associated pneumonia. Am J Respir Crit Care Med 2005;171:388-416.

6. Levin PD, Idrees S, Sprung CL, et al. Antimicrobial use in the ICU: indications and accuracy--an observational trial. $J$ Hosp Med 2012;7:672-8. 